\title{
دراسة كفاءة تثبيط الراتنجات الامينية باستخدام مياه شط العرب
}

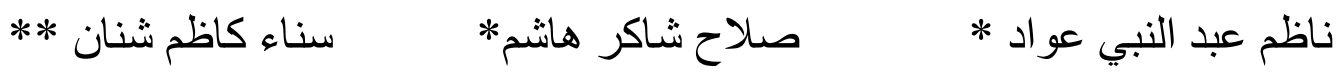 \\ *امعة البصرة - كلية العلوم - قسم الكيمياء \\ ** مديرية شباب ورياضة البصرة - منتدى الر عاية العلمية
}

\section{الخلاصة}

تمت دراسـة كفاءة التنبيط للراتجـات الامينيـة للمركبات الأمين لكنين Amine Liqnin والامين مثنبلول لكنين كعوامل ثتبيط بدرجة حرارة • سمّ ولسبيكتي الحديد الكاربوني والبراص باستخدام مياه شط

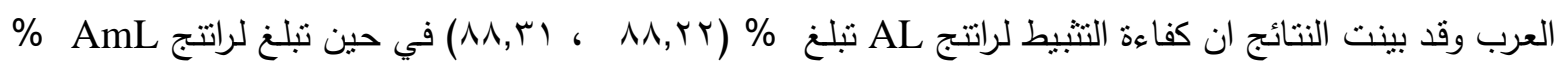

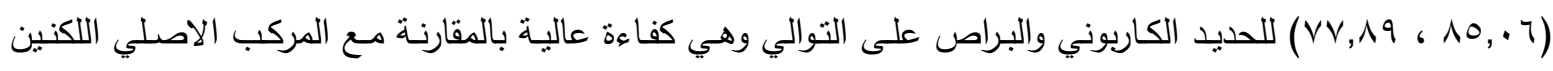
والتي تبلغ \% ( 57.31 , 59.85 ) والسبب في الكفاءة العالية لراتتجي AmL Aو احتواء هذه الراتتجات على المجاميع القطبية الامينية التي تكون غشاء واقياً على سطح المعدن يحميه من التاكل .

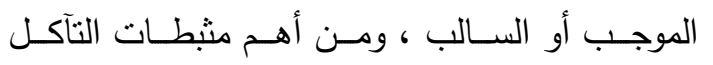
الثـائعة هو اسـتخدام المـواد الكيميائيـة ذات الفعاليـة السطحية وهي المركبات التي تحتوي على مجاميـع قطبية تعزز الانتشـار أو الالتصاق المناسب بالسطح

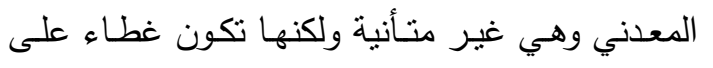

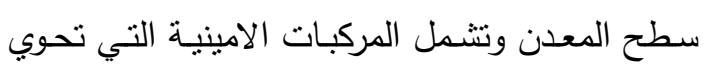

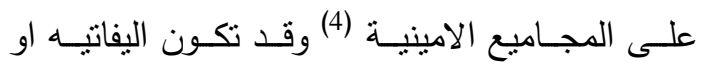

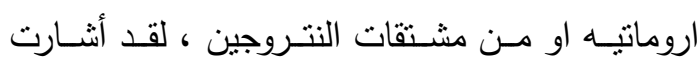
معظم البحوث إلى نجاح استخدام الأمينات كمثبطات

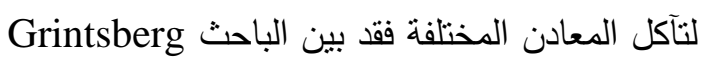

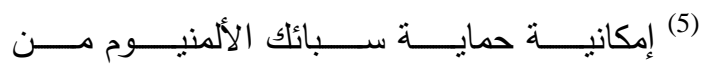

المقدمة التآكــل هـــو تحــول المعــادن أو الســبائك ذات المواصفات الخاصـة لظروف كل استعمال إلى مواد هشـــة بفعـلـ تفــاعلات كيميائيــة أو كهروكيميائيــة

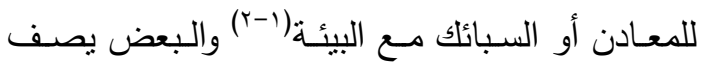
التآكل بأنه نوع من تفاعلات الأكسدة والاختزال الغير

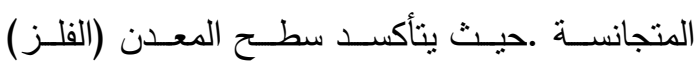
ويختزل المحيط (3) وهناك عدة طرق لتثيط التاكل من

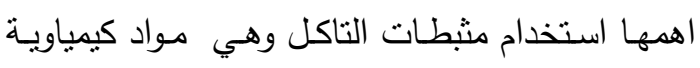
تضاف إلى مزيج التآكل بحيث تؤدي إلى إعاقة سير

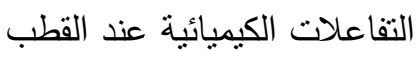


سبيكة الصـلب الطري Mild Steel في محلول حامض الكبريتيك ـ وتم في هذا البحث استخدام AL,

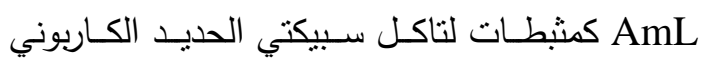

والبراص في مياه شط العرب بدرجة حرارة · "َّم" . الجزء العملي

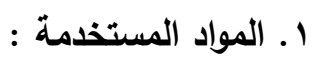

تم استخدم اللكنين نوع كرافت ( Kraft Lignin ) والمجهز من قبل الثركة العامة للصناعات الورقية في

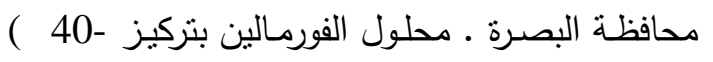
(37 \% بيكاربونـات الصـوديوم المجهزة مـن شـركة . $\mathrm{H} \& \mathrm{~W}$

امـا المواد المجهزة من شركة Fluka فهي ورق كاربيد السليكون مثباين النعومة و حامض الفسفوريك

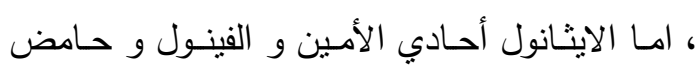
الهيدروكلوريك و الفيوران المهدرج فجهزت من شركة الأنين . B.D.H

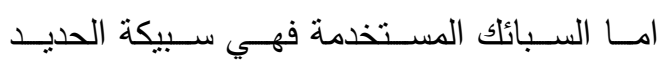
الكاربوني والبراص الجهززة من شركة نفط الجنوب

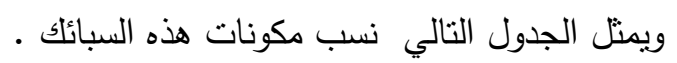

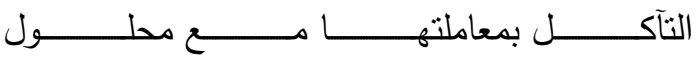
لمدة Cyclohexylaminechromate Solution 7 أيام لتكوين طبقة الاوكسيد الواقية .

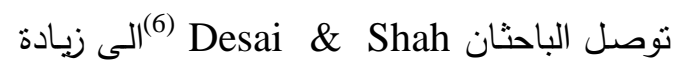

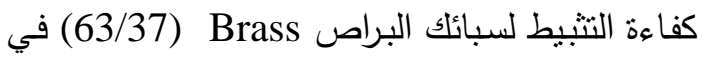
محلول هيدروكسيد الصوديوم المخفف وذلك بإضافة

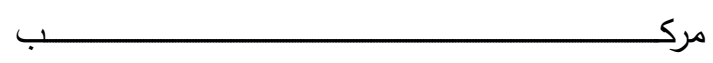
m-and p-amino phenol ولوحظ انه كلما تزداد

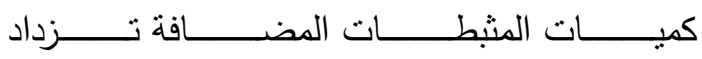
كفاءة التثبيط ـ وبين الباحثان Barbier \& Fiaud

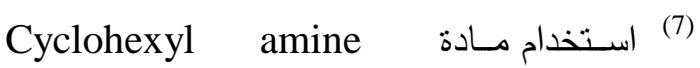
كمثبط لحماية معدن النحاس من التآكل Carbonate في الهواء الجوي ـ وفي دراسـة أخرى بين الباحثان Gronskij \& Maklakova الهيدروكسي أمين hydroxyl amine كثبط لتآكل معدن البراص Brass في حسامض الهيدروكلوريك

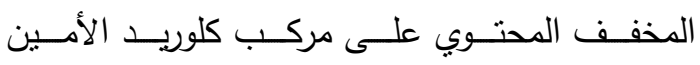
. amineChloride

في حين تمكن الباحثان Misra\& Banerjee في استخدام 1,10-Phenanthroline كمثبط لتنآكل

$$
\text { جدول (1) : يمثل نسب مكونات السبائك }
$$

\begin{tabular}{|c|c|}
\hline 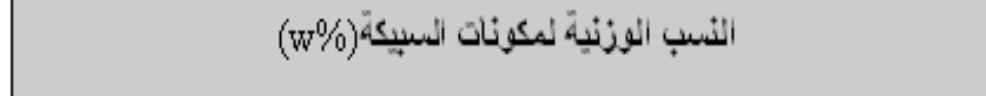 & نوع السيكة \\
\hline Fe, 0.06\% , الوزن المسنبفي & الحديد الكاريبني \\
\hline 1\%, 0.05\%As, 1.2\%Al ,1\% Fe, 28\%Zn, $68.75 \% \mathrm{Cu}$ مكونان أخرى & 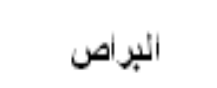 \\
\hline
\end{tabular}




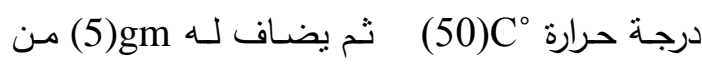
r. الاجهزة المستخدمة : اللكنين أو الراتتج لكنين فورمالديهايد المذاب بكميـة

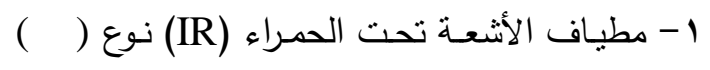
قليلة من الايثانول أمين على شكل قطرات ، وتستمر . Philips والمصنع في شركة Sp3-300S

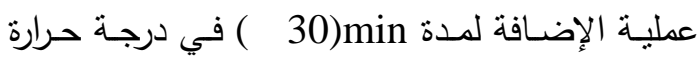

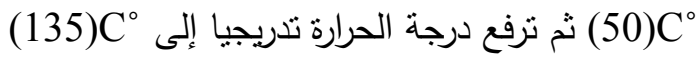

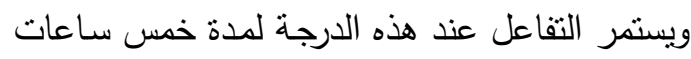

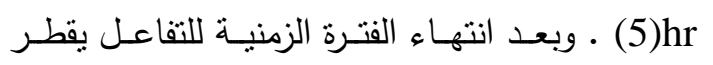
الايثانول أمين الغير متفاعل تحت الضغط المخلخل ، r- جهاز قياس معدل التآكل موديل Corrosion measurement consol 350A )

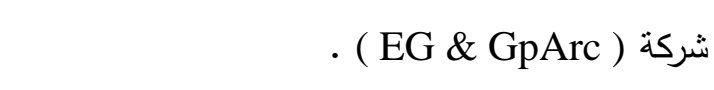

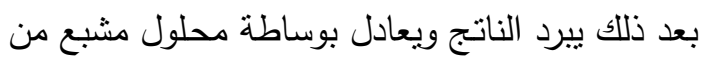
بيكاربونات الصوديوم ، الناتج يذاب باستخدام الكحول

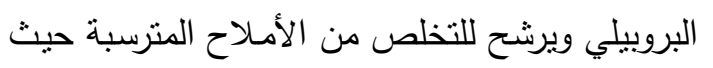

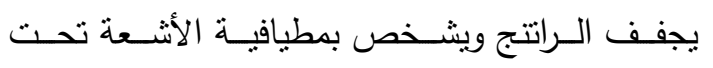

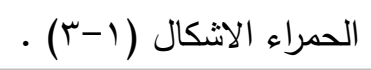
ץ- جهاز الصقل والتتعيم موديل ( 2120 ) والمجهز (

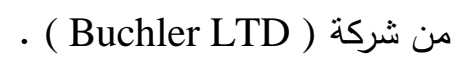

\section{r. تحضير الراتتجات الامينية (10-1)}

يوضسع في وعاء التفاعل حوالي ml (20)

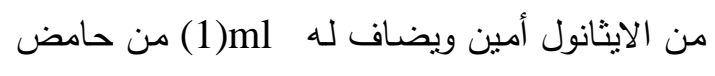

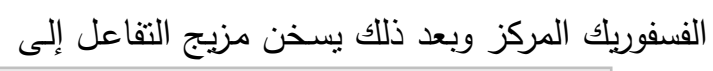
جدول (2) : يوضح التراكيب المقترحة للراتتجات البوليميرية المحضرة

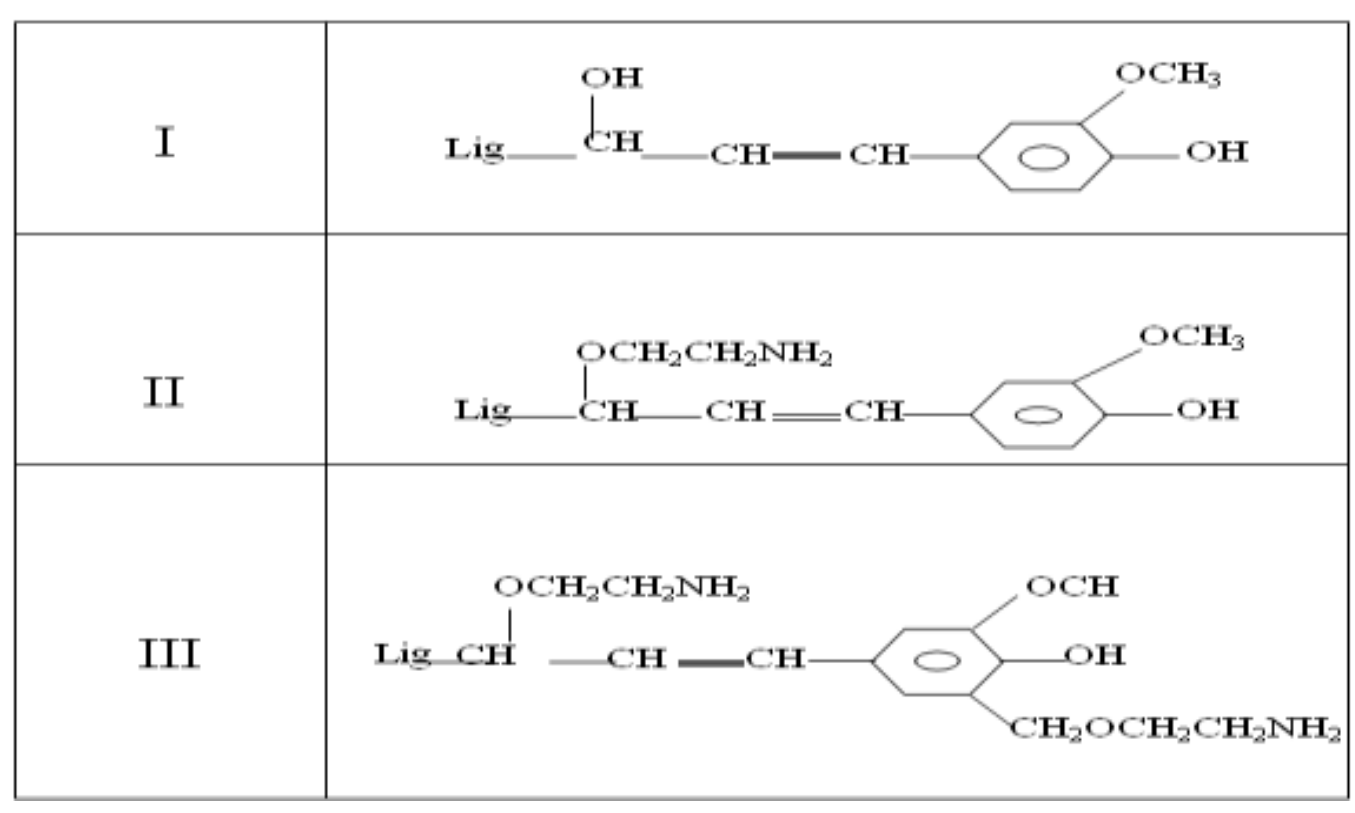

\section{النتائج والمناقشية}

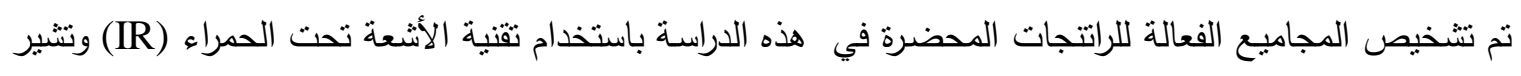

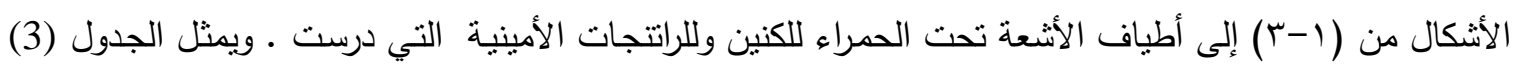

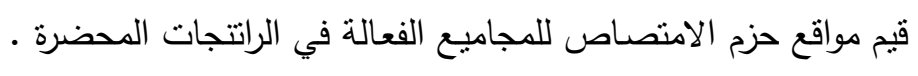



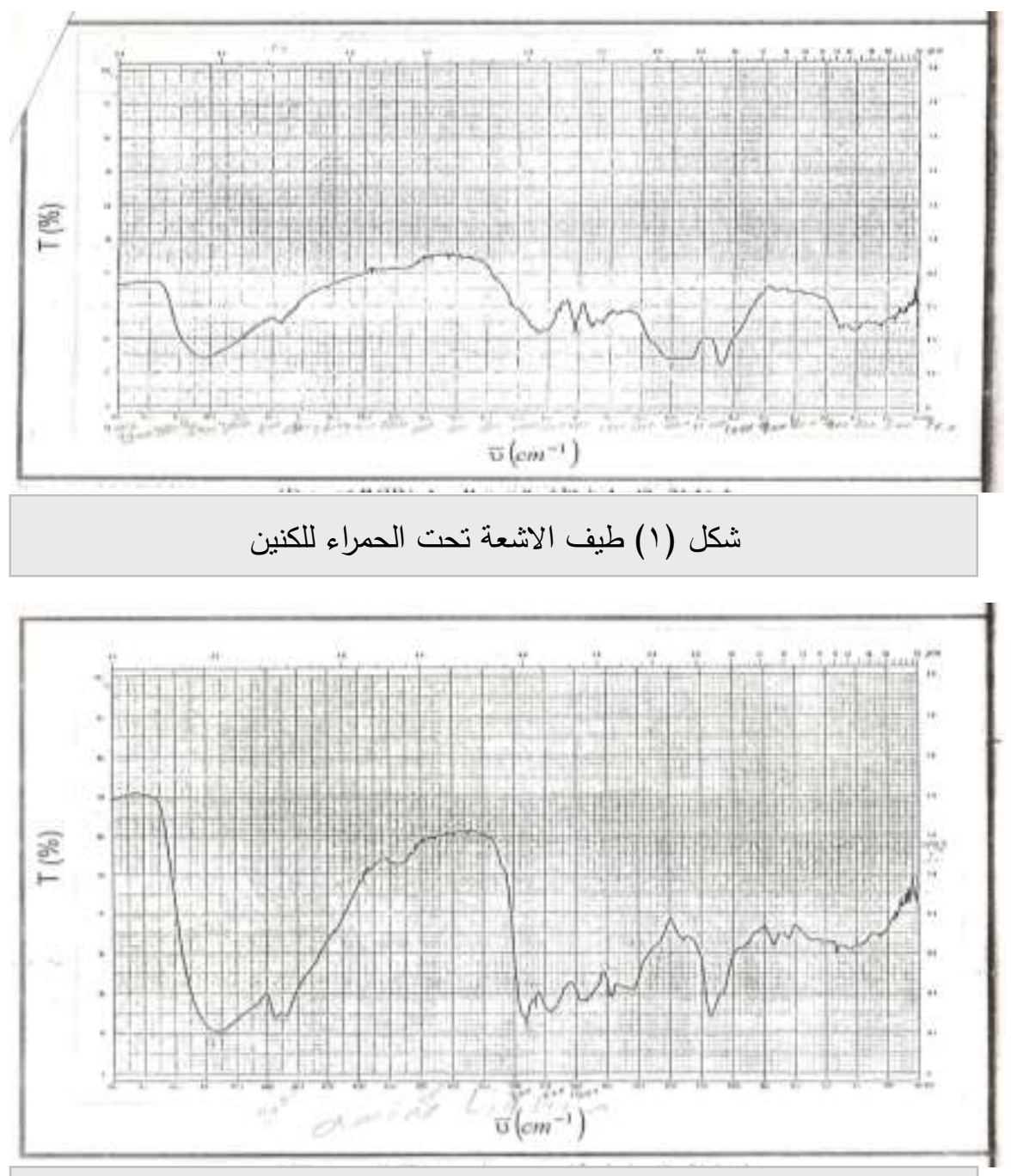

$$
\text { شكل (r) طيف الاشعة تحت الحمراء لراتتج الامين لكنين }
$$

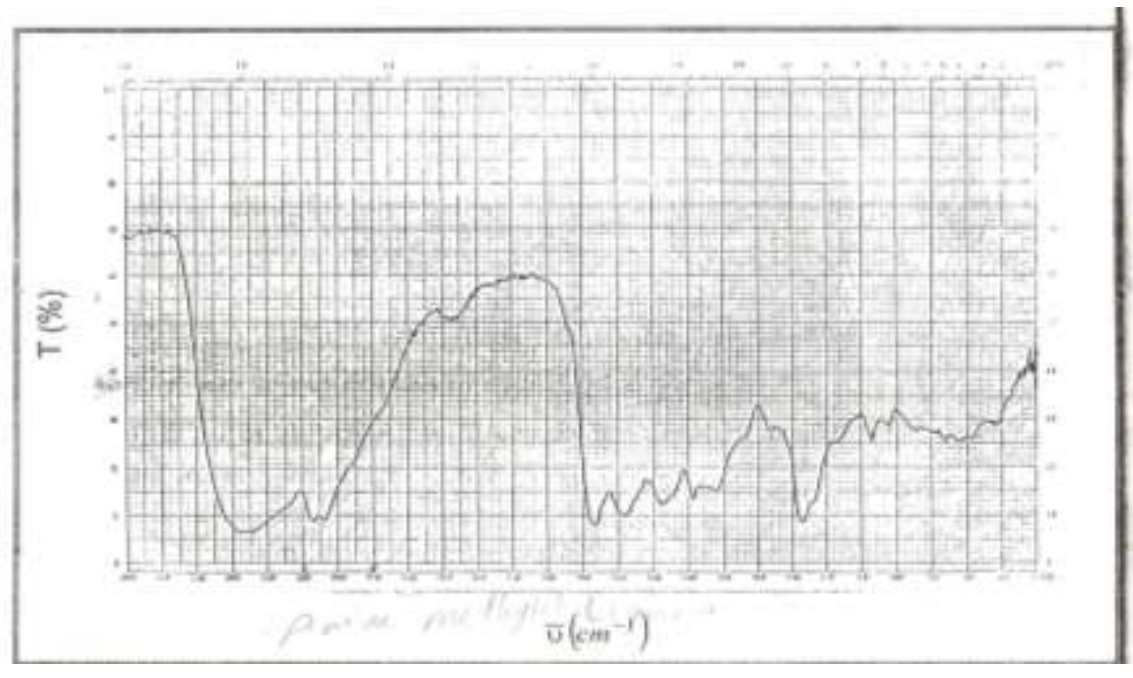

$$
\text { شكل (r) طيف الاشتعة تحت الحمراء لراتتج الامين مثيلول لكنين }
$$


جدول (3) : يمنل حزم الامتصاص للمجاميع الرئيسية للكنين والراتتجات المحضرة

\begin{tabular}{|c|c|c|c|c|c|c|c|}
\hline \multirow{2}{*}{ الر انتتج } & \multicolumn{7}{|c|}{ 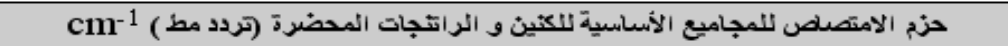 } \\
\hline & $\mathrm{OH}$ & $\mathrm{NH}_{2}$ & $\mathrm{C}-\mathrm{N}$ & $\mathrm{C}=\mathrm{C}$ & $\begin{array}{c}\mathrm{C}=\mathrm{C} \\
\text { aromatic }\end{array}$ & $\begin{array}{l}\mathrm{C}=\mathrm{O} \\
\text { ester }\end{array}$ & $\mathrm{C}-\mathrm{O}-\mathrm{C}$ \\
\hline 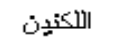 & 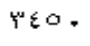 & - & - & หนร. & 104. & - & $1 \cdot \varepsilon \cdot$ \\
\hline al & 3350 & 3300 & ทัย . & 1620 & 1580 & १४४ & 1070 \\
\hline aml & ץ 350 & 3300 & ทัย. & 1625 & 1580 & 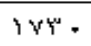 & 1070 \\
\hline
\end{tabular}

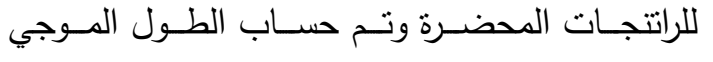
الاقصى والامتصاصية عند الطول الموجي الاقصى

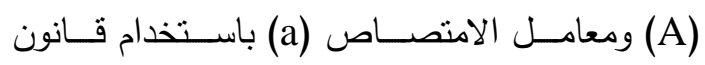

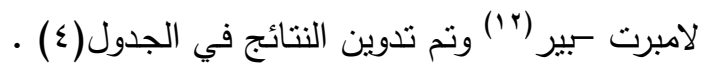

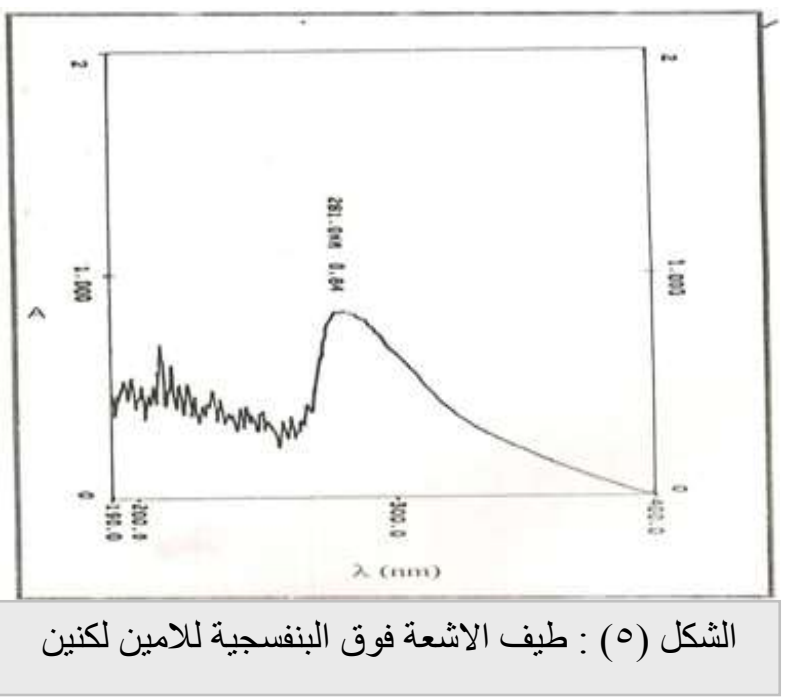

UV Uذلك قيست اطيـاف الاثـعة فوق البنفسـية للكنين والراتتجـات الامينيـة المحضـرة بهيئة محاليـل

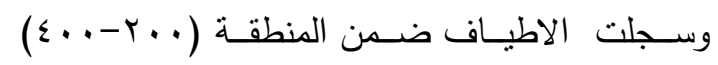
نانوميتز ، وتمثل الاشكال (ع-7) الاطياف

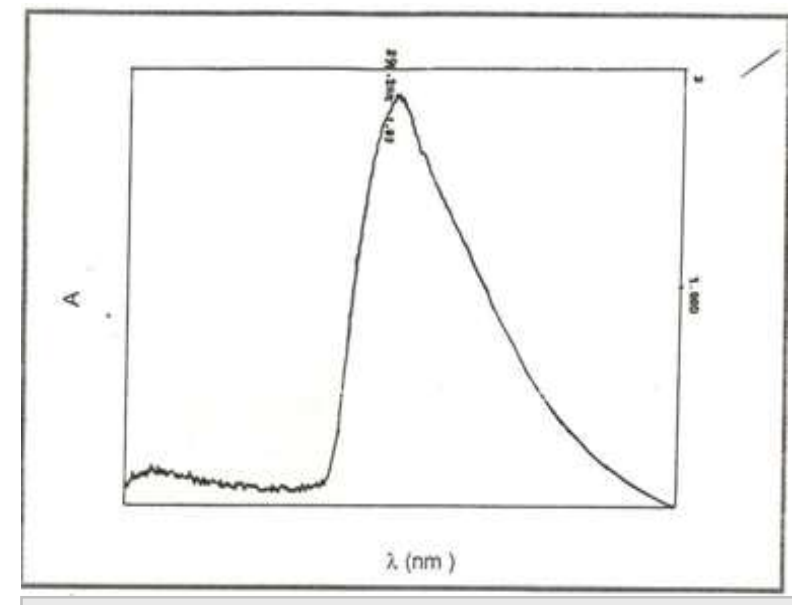

الشكل (ع ) : طيف الاشعة فوق البنفسجية للكنين

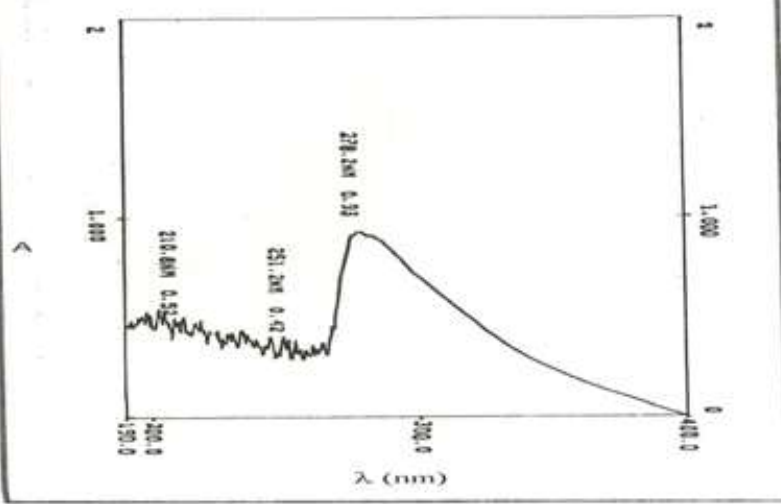

الثكل (ך) : طيف الاشعة فوق البنفسجية للامين مثيلول لكنين 


\begin{tabular}{|c|c|c|c|c|}
\hline ألز أتَّج & غمد / لتيز & $\mathrm{A}$ & لتزر -'. غمد -'، سم -' & ألطول ألموجي \\
\hline ألكنيث & $\cdot, r$ & 1,19 & $4 r$ & rq1,r \\
\hline الامين لكثنين & $\cdot, r$ & $\cdot, \wedge t$ & TA & YAI, \\
\hline الاعين مثيلون لكثين & $\cdot \pi$ &., 94 & ri & $r \vee \Lambda, r$ \\
\hline
\end{tabular}

التـوالي ، بينمـا بلغــت كفـاءة التثبــيط لـراتتج الامـين

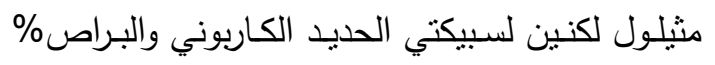

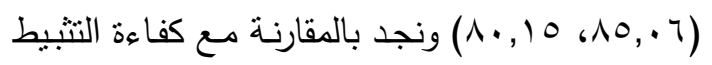

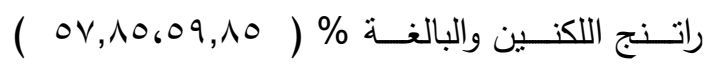
للحديــ الكـاربوني والبـراص على التـوالي ان كفـاءة

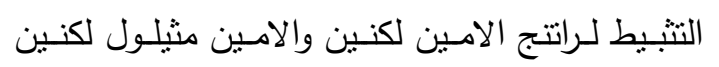
اعلى من اللكنين بسبب احتواءه على مجاميع الامين

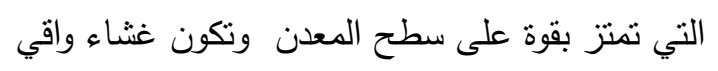
يحمي المعدن مسن التاكل وتسبب نقص في معدل

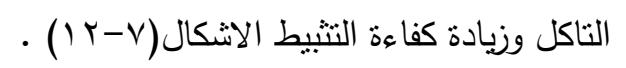

تم قياس معدل التاكل للكنين والراتتجات المحضرة وهي الامين لكنين والامين مثيلول لكنين بدرجة حرارة

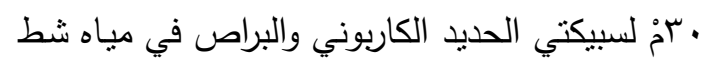

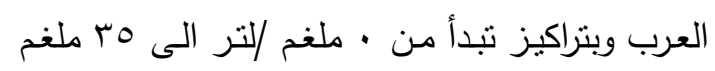

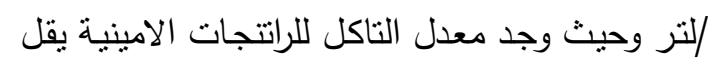
مـع زيـادة المـادة المتبطـة حتى نصـل الـى التركيز المفضل الذي يعطي اقل معدل تاكل بعد ذلك يزداد

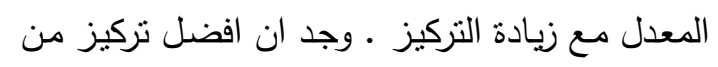

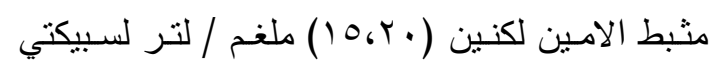
الحديد الكاربوني والبراص على لإنى

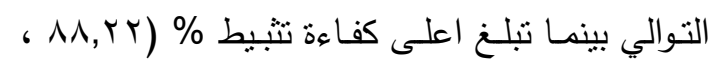

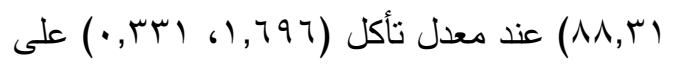

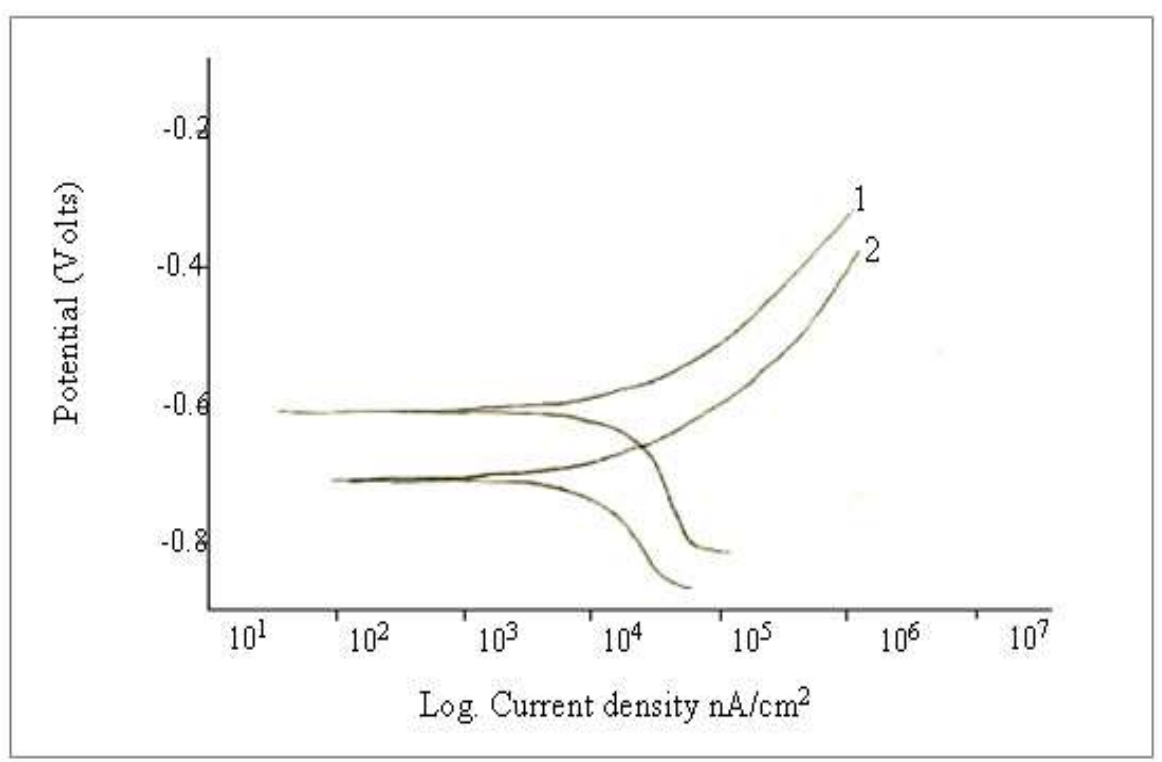

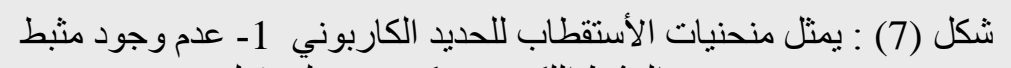

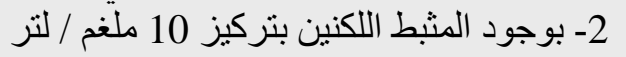




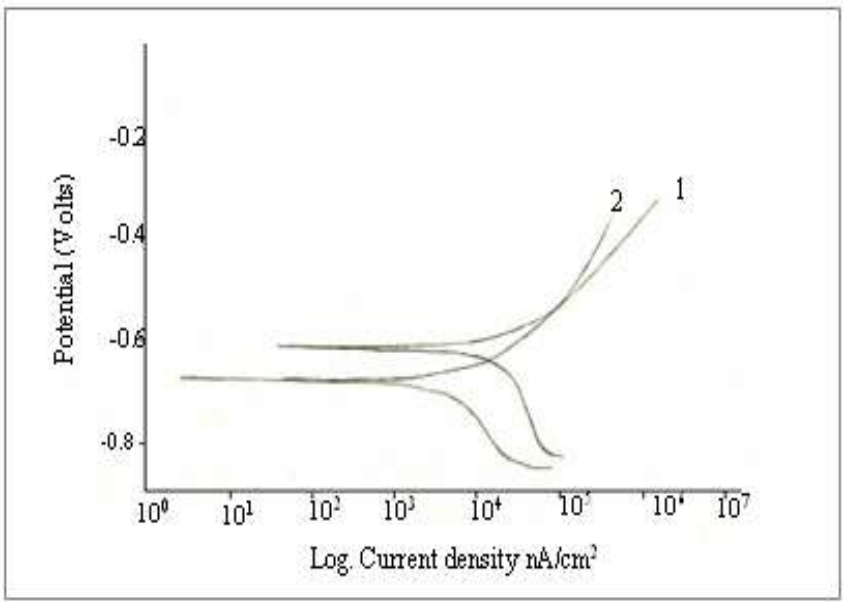

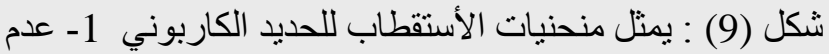

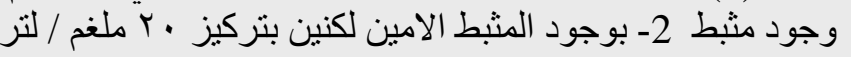

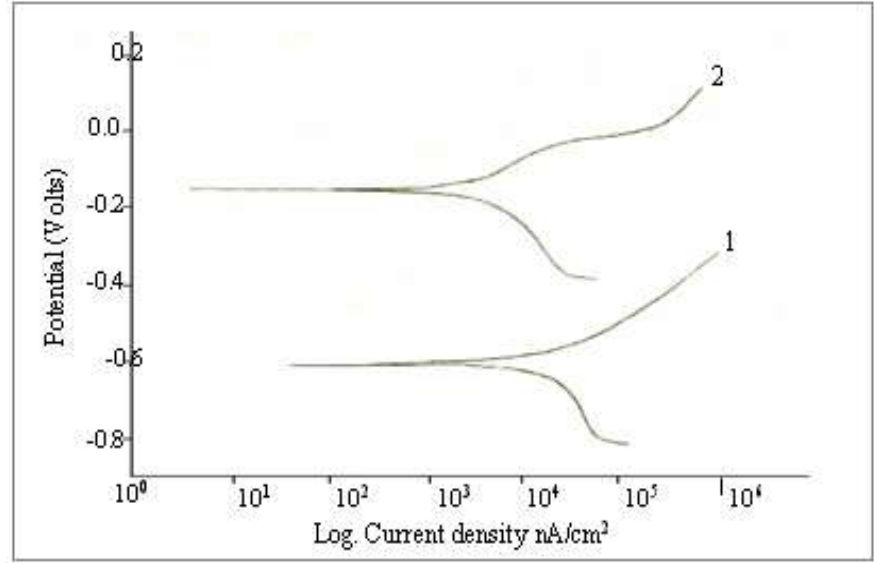

شكل (11) : يمثل منحنيات الأستقطاب البر اص 1- عدم وجود مثبط 2- بوجود المثبط امين مثيلول لكنين بتركيز 25 ملغم / لتر

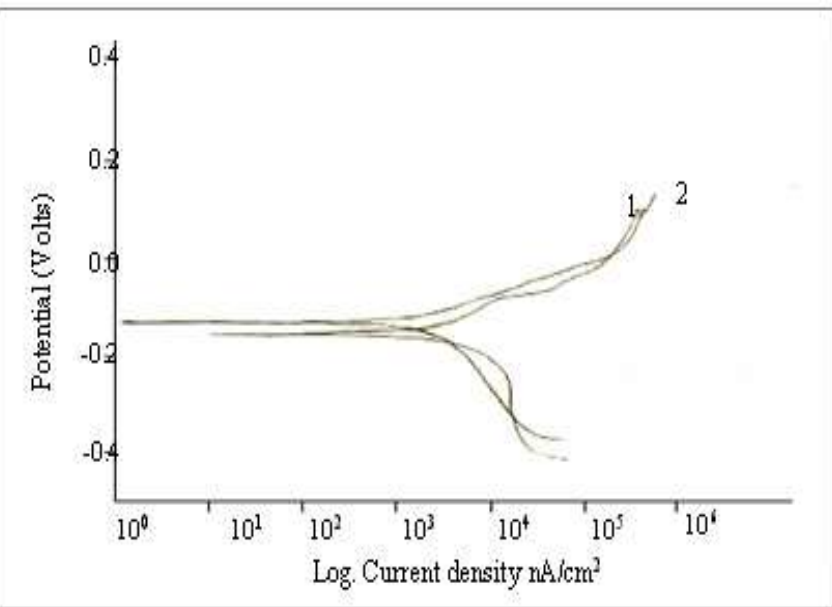

شكل (8) : يمثل منحنيات الأستقطاب للبر اص 1-عدم وجود مثبط 2- بوجود المثبط اللكنين بتركيز 20 ملغم / لتر التر

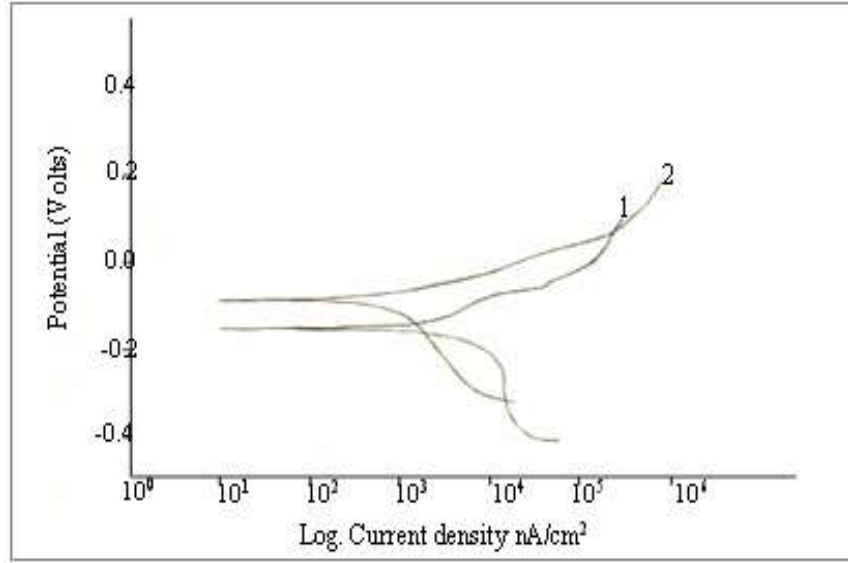

شكل (10) : يمثل منحنيات الأستقطاب للحديد الكاربوني 1- عدم وجود مثنط 2- 10 : بوجود المثبط الامين لكنين بتركيز 15 ملغم / لنر

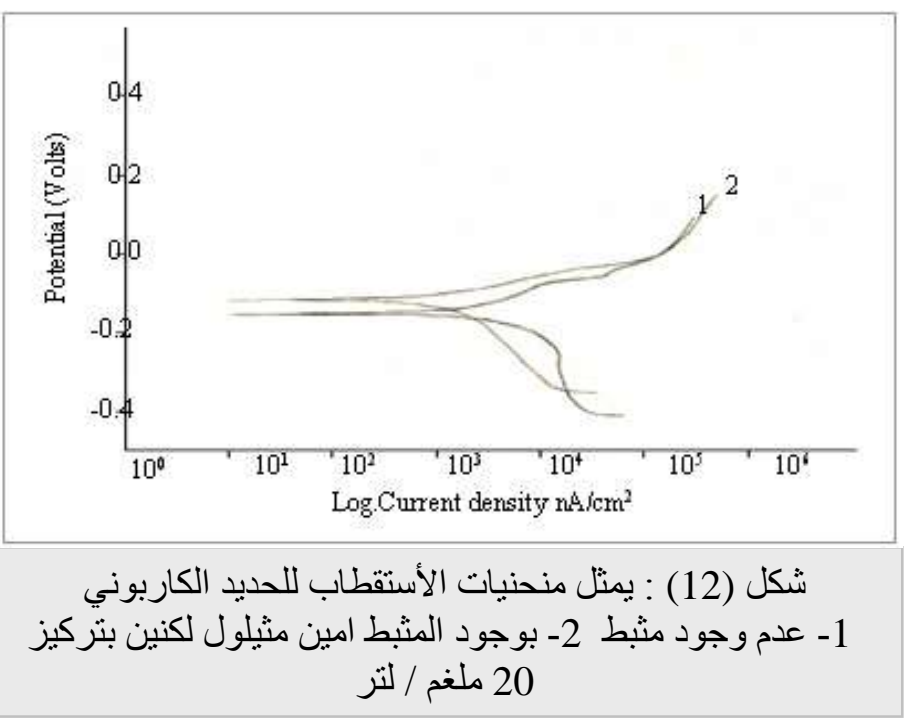


4. A. G. Collins (1975) ; “Geochemistry of Oil field water "; No.1, Amesterdam

5. S. A. Gintsberg ; (1969), Zashchita Metaiiov, 5.

6. M. N. Desai and Y. C. Shah (1970) ; Werkstoffeu. Korrosion , 21(10).

7. J. Barbier and C. Fiaud (1974) ; MetauxCorrosion -Ind. , 49(587/588).

8. R. L. Gronskij and V. P. Maklakova (1978) ; VodopodEdgotovka Vodn. Rezhim. Khimkontrol Parosil . Ustanovkakh , 6 .

9. S. N. Banerjee and S. Misra (1989) ; J.Corrosion , 45 (9) .

10. G. A. Adam (2001) ; National J. of Chemistry ,1,121.

11. H. Z. Al-Swaaid (2000) ; “M.Sc. Thesis " Chem. Dept., College of Science, University of Basrah, Basrah , IRAQ.

12.R.A.Alberty(1987);“physicalChemistry" ;Wiley- interscience,N.Y., $7^{\text {th }}$ Ed.,p943.

13. 82. D. Behrens (1988) ; “Corrosion Hand book "; Vol.3, VCH-Weinheim Germany.

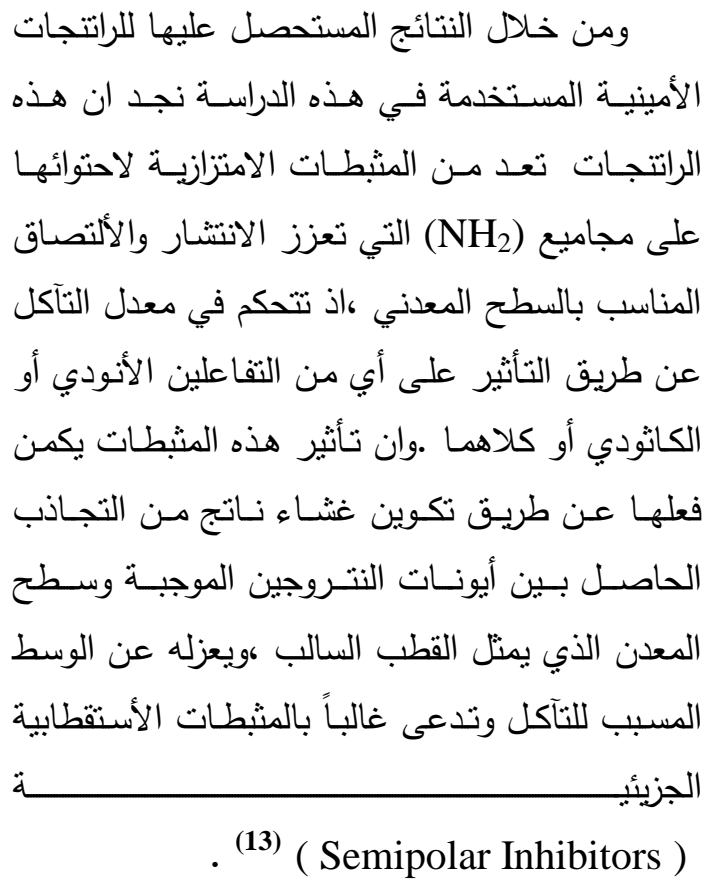

\section{Referenes:}

1. Q. A. Yousif (2001) ; “M.Sc. Thesis ”; Dept. of Chemistry, College of Science, University of Baghdad, Baghdad ,IRAQ.

2. Ullmann's (2002) ; “ Encyclopedia of Ind. Chemistry " ; $6^{\text {th }}$ ed , Electronic Release C, Wiley - VCH Weinhein, Germany .

3. L. L. Shreir (1976) , “ Corrosion Metals / Environment Reaction ", Butter Worths, London . 